\title{
The Relationship between Willingness to Communicate, Locus of Control and Foreign Language Anxiety among Iranian EFL Learners
}

\author{
Farzaneh Ehsani ${ }^{1}$, Qotboddin Jan-nesar Moghaddam²* \\ 1. M.A., Instructor at Payeme Noor University, Fasa center, Fasa, Iran \\ 2. Ph.D., Department of English Language and Literature, Birjand Branch, Islamic Azad University, Birjand, Iran. \\ * Corresponding author's Email: Jannesar_m@yahoo.com
}

\begin{abstract}
This study started with the aim of exploring the relationship between willingness to communicate (WTC), foreign language anxiety (FL anxiety) and locus of control (LOC) among Iranian EFL learners. To conduct this study, a correlation-descriptive design was selected to achieve the objectives. The participants consisted of 80 intermediate (40 males and 40 females) EFL learners randomly selected from among EFL students studying in different branches of Ibne Sina Language institute, Iran. At the beginning, the participants were asked to fill Rotter's (1966) Locus of Control Scale. One week later, Willingness to Communicate (WTC) Questionnaire was given to the participants to be filled by them. One week after that, the researcher gave FL Anxiety Questionnaire to the participants and asked them to fill it. The collected data were analyzed using descriptive statistics and Pearson Product-moment correlation test. The results showed that there was no relationship between WTC and LOC among Iranian EFL learners; there was a significant but negative correlation between WTC and FL anxiety; and LOC and FL anxiety were not significantly correlated. This study has some implications for stakeholders in the field including EFL teachers, EFL learners, and curriculum planners. However, taking the limitations of the present study into account, the obtained results cannot be exclusively true.
\end{abstract}

Keywords: Locus of Control; Internalizers; Externalizers; Willingness to Communicate; Foreign language (FL) anxiety

\section{Introduction}

Language learning styles are among the main factors that help determine how and how well our students learn a second or foreign language. In addition, communication is considered as one of the most prominent functions of language and in order to learn and acquire a new language, the learner must demonstrate willingness to communicate (WTC) in that language. Thus, being able to start the process of communication in an educational context of learning a second language is considered to be a significant element for successful learning. Generally, the notion of willingness to communicate is regarded as a complex concept and is under the influence of other individual differences such as learning styles. The notion of willingness to communicate was originated from the works of Burgoon (1976). She called her concept "Unwillingness to Communicate" and defined it as constant predisposition to avoid or decrease oral communication. According to MacIntyre, Clement, Dornyei, and Noels (as cited in Pattapong, 2010), producing willingness to communicate is a significant element in modern language instruction. Based on the studies of Kang (2005), teachers will have more active learners by making them more willing to communicate. Kang (2005) mentioned that "students with high WTC are more likely to use L2 in authentic communication and function as autonomous learners by making independent efforts to learn language." (p. 234) He also suggested that students with high willingness to communicate will have their learning opportunities and participate in learning activities both inside and particularly outside the classrooms. For the first time, the construct "Unwillingness to Communicate" 
was coined by Burgoon (1976, p. 17) as "enduring and chronic tendency to avoid or devalue oral communication". According to her, an individual's willingness for communication is influenced by variables like anomie, alienation, introversion, self-esteem, and communication apprehension. The concept 'willingness to communicate (WTC)' dates back to the work on communication in a native language in the late 1950s and early 1960s (McCroskey, 1997) in North America. McCroskey and Richmond (as cited in MacIntyre \& Charos, 1996, p.7) defined WTC as a "stable predisposition toward communication". They believed that WTC shows individuals' general personality orientation toward communication in different contexts and their intention to initiate communication. McCroskey and Baer (1985) proposed that WTC is a trait-like and personality-based predisposition that is relatively consistent across different communication contexts and various types of receivers. They devised and validated WTC scale. Therefore, WTC was developed as a consistent tendency for communication in different situations (McCroskey \& Richmond, 1990), and it was conceptualized as a cognitive tendency to speak which is influenced by an individual's personality (McCroskey \& Richmond, 1990). Kang (2005) defined WTC as “... an individual's volitional inclination towards actively engaging in the act of communication in a specific situation, which can vary according to interlocutor(s), topic, and conversational context, among other potential situational variables" (p. 291). MacIntyre, Dornyei, Clement, and Noels (as cited in Pattapong, 2010) stated that WTC in a second language (L2) involves a learner's desire to communicate in a second language when given opportunities. They also continued that learners' inclination to speak leads to an increased frequency of language use.

Regarding the concept of Locus of Control (LOC), it should be said that Rotter (1966) developed this concept which refers to the type of control individuals feel over the situation influences their decisions. Rotter called this feature "Locus of Control" in the 1950s and defined it "as an individual's perception about the underlying main causes of the various events that take place in their lives. In terms of LOC, individuals can be classified as internalizers or externalizers. Internalizers have an internal LOC and externalizers have an external one. This difference leads to different evaluations of successes and failures in individuals. Individuals having an internal LOC perceive themselves as controllers of their life events and attribute their success or failure to internal factors like hard work, decision-making and problem solving skills, effort, etc. (Lefcourt, 2014). Because these individuals believe that internal factors are the sources of their success or failure, they are independent, can better solve their problems and have a high self-concept. In contrary, those having an external LOC attribute their behavior to external factors like luck, fate, chance, and the surrounding people. In other words, they believe that the sources of their failure and success are out of their hands, so, they do not try and just rely on external factors (Lefcourt, 2014).

The third concept investigated in the present study is foreign language (FL) anxiety. FL anxiety is experienced by students in the form of negative experiences in a foreign language context (Chen \& Chang, 2004). Also, language learners may feel anxious due to linguistic difficulties they encounter in the process of language learning and language use (Hashemi \& Abbasi, 2013). Zhang and Zhong (2012) enumerated learners' unrealistic or erroneous beliefs about language learning as the main cause of learners' anxiety. Feelings of lack the aptitude to learn a new language, high expectations, shortage of time, etc. can also cause anxiety in learners (Horwitz, 1988) Anxious learners may also think that their level of language skills are lower than their classmates and this in turn can lead to anxiety in them (Young, 1991). 
Although one of the main goals of English teaching and learning is to communicate and to achieve fluency and this important issue sheds more light on willingness of the learners to communicate and the factors affecting it (MacIntyre, 2007), many Iranian EFL learners have problems with communication and cannot reach a desirable level of communication skill. During their education periods, they gain a high amount of knowledge in the other aspects of English language learning, but most of them complain about their low level of communication ability. In educational environments (including Iranian educational system) in which English is taught as a foreign language, there is not a chance for learners to speak English. So, it is the responsibility of teachers to take useful measures to enhance their students' willingness to communicate.

Besides, the notion of LOC has been proved to be significantly effective in the English learning in EFL contexts (William \& Burden, 2002). It is closely intermingled with the concept of motivation, refers to the type of control individuals feel over the situation influences their decisions (Rotter, 1966). Rotter called this feature "Locus of Control" in the 1950s and defined it "as an individual's perception about the underlying main causes of the various events that take place in their lives. As the concept of LOC regards, it has been developed by Rotter (1966) as a developmental psychologist. To him, the type of control individuals feel over the situation influences their decisions. Rotter called this feature LOC in the 1950s and defined it "as an individual's perception about the underlying main causes of the various events that take place in their lives. It involves the extent to which individuals believe their lives are controlled by themselves or by external factors" (Rotter, 1966, p. 12). It has been argued that LOC significantly influences individuals' academic performance (Lefcourt, 2014). In terms of LOC, individuals can be classified as internalizers or externalizers. Internalizers have an internal LOC and externalizers have an external one. This difference leads to different evaluations of successes and failures in individuals. Individuals having an internal LOC perceive themselves as controllers of their life events and attribute their success or failure to internal factors like hard work, decision-making and problem solving skills, effort, etc. (Lefcourt, 2014). Because these individuals believe that internal factors are the sources of their success or failure, they are independent, can better solve their problems and have a high self-concept. In contrary, those having an external LOC attribute their behavior to external factors like luck, fate, chance, and the surrounding people. In other words, they believe that the sources of their failure and success are out of their hands, so, they do not try and just rely on external factors (Lefcourt, 2014).

In addition, FL anxiety (FL anxiety) debilitates the quality and amount of learning in the form of negative experiences (Chen \& Chang, 2004) and should be more investigated in relationship with the other factors which influence language learning. To Horwitz (1988), FL anxiety is a distinct complex of self-perceptions, beliefs, feelings and behaviors related to classroom language learning and it is contextbased. This anxiety may be generated in the learners as a result of linguistic difficulties they encounter in the process of language learning (Hashemi \& Abbasi, 2013). According to Gardner (2004), FL anxiety is a kind of tension and apprehension which is felt when learning second language skills including speaking, listening, etc. Or as stated by Zhang and Zhong (2012), learners' unrealistic attitudes toward language learning may lead to anxiety. Learners' FL Anxiety is a factor that affects L2 learning. According to Zhang and Zhong (2012), generally, foreign language anxiety (FLA) is a feeling of tension and apprehension which is associated with second language learning contexts, specifically in relation to speaking and listening tasks. Horwitz, Horwitz, and Cope (1986), regarded FL anxiety as a state 
dependent on situation and described it as a distinct complex of self-perceptions, beliefs, feelings, and behaviors which are related to classroom language learning and are rooted in the uniqueness of the language learning process. To them, FLA differs from the anxiety experienced in other fields of learning because this particular type of anxiety imposes sociocultural and linguistic demands on learners. These imply the deterrent role of FLA in language learning. As put by Shao, Yu and Ji (2013, p. 918), "negative emotions such as anxiety, fear, stress, and anger can compromise learners' optimal learning potential and largely reduce their language learning capacity".

The three concepts discussed above have been investigated in the area of English language learning. However, they have not been explored in relationship with each other, at least in the context of Iran. This is while FL anxiety is a debilitating factor for many EFL learners. More importantly, although WTC is of significance in today's global village, many EFL learners are not much willing to communicate in English. To fill this gap, the researcher decided to investigate the relationship between them in the present study. To fulfill the purpose of the present study, the following research questions were addressed:

1. Is there a relationship between willingness to communicate (WTC) and locus of control (LOC) among Iranian EFL learners?

2. Is there a relationship between willingness to communicate (WTC) and Foreign language anxiety (FL anxiety) among Iranian EFL learners?

3. Is there a relationship between locus of control (LOC) and Foreign language anxiety (FL anxiety) among Iranian EFL learners?

\section{Literature Review}

Empirical Studies on WTC: Shahsavani, Shasavar and Sahragard (2014) investigated the relationship between WTC and identity processing styles among advanced Iranian learners of English as a foreign language using WTC questionnaires. According to the finding of the study, the information identity processing style was the strongest predictor of WTC levels. Also, identity style subscale could account for 77\% of WTC variance. Zarrinabadi and Haidary (2014) investigated the relationship between WTC and identity styles of Iranian EFL learners. Data analysis indicated that there is a positive correlation between WTC and self-perceived communication competence, and informative and normative identity styles. But, there was a negative correlation between WTC and self-perceived communication competence, and diffuse-avoidance. Yousefi and Kasaian (2014) examined the possible relationship between WTC and speaking fluency and accuracy among Iranian EFL learners. The results confirmed the existence of a positive relationship between WTC and speaking fluency. Based on the results, the researchers concluded that both trainers and trainees may benefit from WTC to increase fluency and accuracy level of learners' speaking. Valadi, Rezaee and Kogani Baharvand (2015) conducted a study with the aim of investigating the relationship between language learners' WTC and their oral language proficiency in terms of gender differences. The results revealed a significant relationship between learners' WTC and their oral proficiency. However, gender did not have a significant effect in this regard. In another study, Zohrabi and Yousefi (2016) aimed at examining the relationship between reflective teaching, WTC, intrinsic motivation and language proficiency of Iranian EFL learners. 
Findings indicated that there was a significantly positive relationship between reflective teaching, WTC, intrinsic motivation and proficiency test scores of the participants.

Empirical Studies on LOC: Rahimi and Askari Bigdeli (2014) sought to explore the relationship between EFL learners' LOC and their vocabulary learning strategies. Besides, the researchers were aimed at investigating the role of gender in the mentioned relationship. To this aim, both male and female students participated in the study. Tools employed for data collection purposes were Rotter's Locus of Control Scale (1966) and a researcher-made questionnaire designed based on Li's (2004) Vocabulary Learning Strategies Questionnaire. University of Kashan and Allameh Tabataba'i University constituted setting of the study. Statistical tests used in the study were Pearson product moment correlation and independent samples t-test. Data analysis showed no significant association between EFL learners' LOC and vocabulary learning strategies. Besides, no significant role was found for the variable of gender in the relationship between LOC and vocabulary learning strategies. Ashraf and Abtahi (2014) did a study with the aim of investigating the relationship between Iranian EFL learners' social cultural capital, their LOC and oral proficiency (listening and speaking). The other aim of the study was exploring the relationship between social cultural capital and LOC. Sample of the study consisted of upper intermediate male and female EFL learners studying at Mashhad language institutes. The study instruments were Social Cultural Capital Questionnaire (Pishghadam, Noghani \& Zabihi, 2011) and the Persian version of LOC questionnaire (Ghonsooly \& Elahi, 2010). The participants' GPA of their Listening and speaking exams were taken as indicators of their oral proficiency level. It was found that there is a positive and significant correlation between social cultural capital, LOC, and students' oral proficiency. Moreover, a significant relationship was found between social cultural capital and LOC. Chalak and Nasri (2015) tried to investigate the relationship between LOC, academic achievement and biological variables among Iranian online EFL Learners. To do so, 100 male and female students studying at Iran Language Institute (ILI), Isfahan, Iran was selected as the participants. The required data were collected through Trice Academic LOC questionnaire and GPAs of the students as indicators of their academic achievement. Data analysis showed no significant effect of gender on the participants' LOC, no significant relationship between LOC and academic achievement, and no significant relationship between LOC and academic achievement. The researchers attributed the findings to the potential change in socio-cultural patterns of gender and recommended sociologists and psychologists to take these changes and their effects on the learners' LOC into account. Hill (2016) conducted a study to examine the relationship between LOC, academic functioning and discipline problems among high school students. To this aim, the researcher used Rotter's LOC measure; the students' state-wide test scores and their discipline records. No statistically significant difference was found among the participants in terms of their LOC. Further, it was shown that test scores and discipline referrals are negatively associated. In a study by Katirayifar and Rezvani (2017), the effect of locus of control (LOC) on language anxiety and test scores was investigated among Iranian EFL learners. Participants included 130 students studying in the field of English translation at Sobhe Sadegh Institute of Higher Education. Instruments used in the study included three TOFEL reading comprehension texts (used to homogenize participants at the outset of the study in terms of their English reading comprehension proficiency), Trice Academic Locus of Control Scale (1985) (to identify the participants' LOC) and Language Anxiety Scale (LAS) (Cassady \& Jonson, 2002) (to measure the participants' level of language anxiety). Data analysis was conducted using correlation test and 
regression analysis. The results showed a significant negative effect of external LOC on the participants' language anxiety and test scores. In spite of this, a significant positive effect of internal LOC on the participants' language anxiety and test scores was proved.

Empirical Studies on FL Anxiety: In a mixed-method study, Kruk (2015) investigated the changes in motivation, language anxiety and boredom in learning English in Second Life. The sample consisted of 16 second year students of English philology. The study was conducted over the period of a summer semester. During that time the participants of the study were asked to use Second Life and practice English there in their own time. The data were obtained by means of a background questionnaire and session logs and subjected to quantitative and qualitative analysis. The results show that the students declared quite high level of motivation to learn English in Second Life, low level of anxiety and relatively low level of boredom. In addition, the findings of the study revealed that both the reported motivation as well as the experience of boredom fluctuated over time. In contrast, the levels of foreign language anxiety declared by the subjects remained almost unchanged. Wu and Lin (2016) examined the relationship between learning strategies and English writing anxiety. Participants of the study were English language learners with Limited English Proficiency (LEP) in a university in Taiwan. Data analysis was conducted using Kruskal Wallis Test. It was found that learning strategies and English writing anxiety are not significantly correlated. In addition, it was indicated that ELLs had a high writing anxiety. In an exploratory study on FL anxiety, Bhatti, Memon and Pathan (2016) investigated the perceptions of English language learners on language learning Anxiety in EFL classroom. The modified form of Foreign Language Classroom Anxiety Scale (FLCAS) by Horwitz et al. (1986) was employed to collect the data. Findings of this study led to identification of the following sources of anxiety among the participants: communication apprehension, the learners' self-perceived proficiency, fear of being negatively evaluated and nervousness. Talebi Rezaabadi (2016) investigated the relationships between the social anxiety, social class and listening-test anxiety of students learning English as a foreign language. The aims of the study were to examine the relationship between listening-test anxiety and listening-test performance. The data were collected using an adapted Foreign Language Listening Anxiety Scale and a newly developed Foreign Language Social Anxiety Scale. The potential correlation between social anxiety and listening-test performance was investigated by the correlation coefficient. A moderate positive correlation was found between students' social class and social anxiety. The results suggest that pedagogical methods suggested to lessen this anxiety were effective. There was also a clear relationship between social anxiety, listening-test anxiety and listening performance. Balla (2017) investigated the level of anxiety due to learning English as a foreign language. To achieve this aim, the Foreign Language Anxiety Classroom Scale (FLACS) was used as the instrument. The data was collected and statistically analyzed through SPSS. Results indicated that anxiety was one of the major factors that impeded English proficiency. Besides, anxiety also caused fear of communication among the students. In a smilar study by Mohammed Sadiq (2017), the level of foreign language anxiety among English language learners was investigated. This study was carried out with a quantitative research design using a survey methodology to collect data about the participants' language anxiety. The sample of the study included 100 university students from the college of Education at Princess Nora University in the Kingdom of Saudi Arabia. The participants were randomly selected. For this research study, Foreign Language Classroom Anxiety Scale developed by Horwitz, Horwitz, and Cope (1986) was used to collect the research data. Communication apprehension, fear of negative evaluation, and self- 
perceptions of language proficiency were identified as the main reasons for language anxiety from the participants' viewpoints.

\section{Material and Methods}

Design: The stated objectives of the study were of a nature that a correlation-descriptive design was appropriate for achieving them. As name speaks for itself, this type of design describes the pattern of relationship between two variables. The two variables under investigation in this study were FL anxiety, LOC and WTC.

Participants: The participants consisted of 80 intermediate (40 males and 40 females) EFL learners randomly selected from among EFL students studying in different branches of Ibne Sina Language institute, Iran. In fact, statistical population consisted of all intermediate male and female EFL learners studying in different language institutes. The participants were from different ages in the range of 2030. All the participants were native speakers of Farsi who were learning English as a foreign language (EFL). To comply with morality issues, first, the consent of the participants was taken to participate in the study. Then, they became informed of the objectives of the study and the contribution of this study to the field.

\section{Instruments}

The process of data collection in this study was accomplished with the following instruments:

WTC Questionnaire: Willingness to communicate context (WTC) scale in a foreign language questionnaire, developed by MacIntyre, et al. (2001) and modified by Hamzehnejad and Shariati (2014) (See Appendix) was used to measure WTC. The scale comprises of 27 items on a 5-point Likert scale ranging from " $1=$ almost never willing" to " $5=$ almost always willing". Reliability of the test was calculated through Cronbach's Alpha as .70 and its content validity was confirmed by expert judgment. 
Locus of Control Scale: In order to determine the participants' LOC, the researcher used Rotter's (1966) Locus of Control Scale. This scale consists of 29 two-choice items. While this scale was already validated, for the purpose of this study, Cronbach's Alpha reliability of it was obtained as .70 and experts confirmed its validity.

The Foreign Language Classroom Anxiety Scale (FLCAS): The Foreign Language Classroom Anxiety Scale (FLCAS) (taken from Shao, Yu \& Ji, 2013) was used to measure the participants' FL anxiety. It consists of 31 Likert items: $1=$ strongly disagree, $2=$ disagree, $3=$ neutral, 4=agree, and $5=$ strongly agree. Cronbach's Alpha reliability of the questionnaire was .79 and it was validated by expert judgment.

Procedures: At first, the study sample was selected from the target population. This procedure consisted of random selection of 80 intermediate male and female EFL learners from EFL students who were studying in different branches of Ibne Sina Language institute, Iran. Due do research ethics and morality issues, the next stage included taking the consent of the participants to participate in the study. Then, the researcher informed the participants of the aims of the study and the reasons for taking such a study. In the next stage, Rotter's (1966) Locus of Control test was distributed among the participants to be filled. One week later, Willingness to Communicate Questionnaire was distributed among the participants and they were asked to complete it. One week later, the researcher gave FL Anxiety Questionnaire to the participants and asked them to fill it. Before, distributing the questionnaires, the necessary instructions were explained to the participants. It is worth mentioning that the questionnaires were distributed through different social networks.

Data Analysis: Both descriptive and inferential statistics were used for the purpose of data analysis. The statistical tests used to answer the research questions included descriptive statistics and Pearson Product Moment correlation test. Indeed, because there were three research questions in the present study, three correlation tests were run in the study. All the analyses were performed via the SPSS package.

\section{Results}

Results of Descriptive Statistics for the Three Variables: This part of the study presents the results of descriptive statistics for Willingness to Communicate (WTC), Locus of Control (LOC) and Foreign Language (FL) Anxiety. Table 1 shows these results:

Table 1. Descriptive Statistics for the Three Variables

\begin{tabular}{|l|c|c|c|}
\hline Variable & Mean & SD & N \\
\hline LOC & 8.60 & 2.51 & 80 \\
\hline FL Anxiety & 59.00 & .71 & 80 \\
\hline WTC & 48.91 & 1.65 & 80 \\
\hline
\end{tabular}

Results of descriptive statistics for the variable LOC shows the mean of 8.60. In addition, standard deviation was 2.51. Regarding the variable FL Anxiety, the mean and standard deviation were 59.00 and .71, respectively. And finally, a mean and standard deviation of 48.91 and 1.65 were obtained for WTC. 
Results of the Relationship between Willingness to Communicate (WTC), Locus of Control (LOC) and Foreign Language (FL) Anxiety: For assessment of the relationship between WTC, LOC and Foreign Language (FL) Anxiety, Pearson correlation analysis was employed. Table 2 presents the results. The results showed that there is a weak positive correlation between WTC and LOC among EFL learners. The coefficient of correlation for these two variables is not significant statistically $(\mathrm{r}=.10, \mathrm{P}>$ $.05)$.

In order to determine if there is a correlation between the other two variables under consideration in this study (i.e., WTC and FL anxiety), another Pearson Correlation test was run (table 2). As shown by the results of the correlation test, there is a significant correlation $(r=-.50, \mathrm{P}<.05)$ between WTC and FL anxiety. However, as seen in the table 2, the sign of the correlation coefficient is negative. That is, higher WTC is associated with lower FL anxiety.

Investigating the relationship between the relationship between LOC and FL anxiety required running another correlation test the results of which are shown in the Table 2. The results showed that there was no statistically significant $(\mathrm{r}=-0.14, \mathrm{P}>0.05)$ correlation between LOC and FL anxiety. This indicates that variation in LOC is not explainable by variation in FL anxiety. Besides, the weak correlation observed was negative. This shows that higher LOC is related with lower FL anxiety, but in a statistically insignificant way.

Table 2. correlation matrix of LOC, WTC and FL Anxiety

\begin{tabular}{|l|l|l|}
\hline Variable & WTC & LOC \\
\hline LOC & .10 & \\
\hline FL anxiety & $-.50 *$ & -.14 \\
\hline
\end{tabular}

$* \mathrm{P}<.01$

\section{Discussion}

As seen in the reviewed literature, while several studies have been conducted on WTC, LOC and FL anxiety in the realm of English learning, so far, to the best knowledge of the researcher, no study has dealt with the relationship between LOC, WTC and FL anxiety among Iranian EFL learners. This study sought to fill this gap.

The results showed that the correlation between WTC and LOC was positive but insignificant among EFL learners. This means that as WTC increases or decreases, there is a lower likelihood of any change in LOC. In other words, it cannot be said that as WTC increases or decreases, there is a better chance of LOC increasing or decreasing. This finding is a justification to give a negative answer to the first research question 'Is there a relationship between willingness to communicate (WTC) and locus of control (LOC) among Iranian EFL learners?' This finding is similar to the study implemented by Ghasemzade and Saadat (2011) who showed no significant relationship between WTC and LOC. Similarly, this result is supported by Bozorgi (2009) who conducted a study to investigate the correlation between LOC and WTC. He found that the obtained correlation coefficient for the relationship between LOC and WTC is not statistically significant. Furthermore, Rahimi and Askari Bigdeli's (2014) results which showed no significant association between LOC and WTC confirm the result of the current study. In a similar vein, the study by Chalak, Nasri and Heidari Tabrizi (2014) wherein the researchers showed no significant relationship between LOC and WTC is consistent with the present study. This repeatedly found insignificant relationship between LOC and WTC may be the sign that different cognitive mechanisms are at work in these two concepts. 
Furthermore, as shown by the results, there was a significant but negative correlation between WTC and FL anxiety. This means that as WTC increases, FL anxiety decreases in a significant way. Accordingly, the second research question 'Is there a relationship between willingness to communicate (WTC) and Foreign language anxiety (FL anxiety) among Iranian EFL learners?' is positively answered. This finding is consistent with Manipuspika's (2018) study which uncovered a strong correlation between learners' foreign language classroom anxiety and their willingness to communicate. This finding is also in the same direction with McCroskey \& Richmond (1990) who stated that willingness to communicate is affected by individuals' anxiety. The same finding was reported by Baran-Lucarz (2021) when he argued that FL anxiety is among the negative contributors to WTC in EFL contexts.

The last finding shown by the results was that LOC and FL anxiety were not significantly correlated. According to this, it can be said that any increase or decrease in LOC is not likely to lead to an increase or decrease in FL anxiety. This leads us to give a negative answer to the third research question 'Is there a relationship between locus of control (LOC) and Foreign language anxiety (FL anxiety) among Iranian EFL learners?' Consistent with this study, Mousavi, Rezaei, Atefi Karajvandi and Javanparast (2018) found no interplay between LOC and anxiety. This finding is also consistent with the findings of a study by Katirayifar and Rezvani (2017) in which the effect of LOC on anxiety was investigated among Iranian EFL learners. Data analysis was conducted using correlation test and regression analysis. The results showed no effect of LOC on the participants' anxiety.

\section{Conclusion}

As argued above, one of the main functions of language is communication and acquiring a new language requires demonstrating WTC in that language. As put by MacIntyre, Clement, Dornyei, and Noels (1998), WTC is a significant element in language learning. Therefore, teachers should make students more willing to communicate (Kang, 2005). This effort shows its significance if we refer to Kang's (2005) statement that "students with high WTC are more likely to use L2 in authentic communication and function as autonomous learners by making independent efforts to learn language" (p. 234). But, the opinion of many teachers is that many students have a low level of WTC, and even some students do not show any WTC.

Furthermore, it has been repeatedly mentioned by scholars in the field that the sources the students attribute their success to which or their LOC contribute significantly to their motivation and their willingness to succeed in language learning. That is, whether students regard themselves and other controllable factors or others and uncontrollable factors as responsible for their learning is a significant issue in the quality of learning.

Moreover, many students experience FL anxiety in a foreign language context (Chen \& Chang, 2004) due to linguistic difficulties they encounter in the process of language learning and language use (Hashemi \& Abbasi, 2013), their unrealistic and erroneous beliefs about language learning, feelings of lack the aptitude to learn a new language, high expectations, shortage of time, etc. This type of anxiety has proved to be negatively associated with language proficiency in different studies.

With a view to the above arguments, this study was set out with the aim of investigating the relationship between the three factors namely, WTC, LOC and FL anxiety. The results showed that there is no relationship between WTC and LOC among Iranian EFL learners. Besides, it was shown that there is a significant but negative correlation between WTC and FL anxiety. In addition, it was revealed that LOC and FL anxiety are not significantly correlated. However, taking the limitations of the present study into 
account, the obtained results cannot be exclusively true. As a main limitation, the size of the sample was not that much large. The other limitation was that the researcher could not select a broader setting for the study, and this can be a threat to the validity of the findings and generalization of the results to new situations.

This study has some implications for stakeholders in the field including EFL teachers, EFL learners, and curriculum planners. EFL teachers become aware of the issue that being externalizer or internalizer is not associated with the amount of WTC and FL anxiety. It is also revealed for them that if their students are more anxious in learning English, their WTC is lower. EFL learners learn that they should try to lower their amount of FL anxiety so that they become more willing to communicate in English language. Curriculum planners are recommended to plan the future EFL curricula so that students become more engaged in the materials and their WTC is increased. In this way, their EF anxiety is decreased.

Conflict of interest: The authors state no conflict of interest in the study.

Financial sponsor: The authors acknowledge that they have not received any financial support for all stages of the study, writing and publication of the paper.

Acknowledgment: We hereby appreciate all the participants of the study as well as all those participating in the implementation of this project.

\section{References}

Ashraf, H., \& Abtahi, T. (2014). On the relation of locus of control, social and cultural capital and oral proficiency achievement of EFL students: A case of Iranians in Mashhad. International Journal of Applied Linguistics \& English Literature, 3 (2), 242-247.

Balla, A.A.S. (2017). Foreign language anxiety in Saudi classroom: A case study of Saudi tertiary female students in Prince Sattam University. English Language Teaching, 10 (5), 28-36.

Baran-Łucarz, M. (2014). The link between pronunciation anxiety and willingness to communicate in the foreign-language classroom: The Polish EFL context. Canadian Modern Language Review, 70(4), 445-473.

Bhatti, N., Memon, Sh., \& Pathan, H. (2016). Investigating the perceptions of Pakistani English language learners on language learning anxiety in EFL classroom. Advances in Language and Literary Studies, 7 (5), 23-34.

Bozorgi, S. (2009). On the relationship between locus of control and the grade point average of the Iranian Azad University EFL students. Retrieved from https://files.eric.ed.gov/fulltext/ED505569.pdf

Burgoon, J. K. (1976). The unwillingness to communicate scale: Development and validation. Communication Monographs, 43(1), 60-96. 
Chalak, A., \& Nasri, N. (2015). The interplay of locus of control, academic achievement, and biological variables among Iranian online EFL learners. International Journal of Cognitive and Language Sciences, 9 (8), 2651-2655.

Chalak, A., \& Nasri, N., \& HeidariTabrizi, H. (2014). The relationship between the types of locus of control and the academic achievement of Iranian online foreign language learners. Cypriot Journal of Educational Sciences, 9 (1), 50-56.

Chen, T.U., \& Chang G.Y (2004). The relationship between Foreign language anxiety and learning difficulties. Foreign Language Ann, 37(2), 279-289.

Ghasemzadeh, A., \& Saadat, M. (2011). Locus of control in Iranian university student and its relationship with academic achievement. Procedia - Social and Behavioral Sciences, 30, 2491 2496.

Hashemi M., \& Abbasi, M. (2013). The role of the teacher in alleviating anxiety in language classes. Int. Res. J. Appl.Basic Sci, 4(3), 640-646.

Hill, R. (2016). Locus of control, academic achievement, and discipline referrals. Murray State Theses and Dissertations. Paper 1.

Horwitz, E. K. (1988). The beliefs about language learning of beginning university foreign language students. Modern Lang. J, 72(2), 283-294.

Horwitz, E.K., Horwitz, M.B., \& Cope, J. (1986). Foreign language classroom anxiety. Modern Language Journal, 70(2), 125-132.

Kang, S.J. (2005). Dynamic emergence of situational willingness to communicate in a second language. System, 33(2), 277-292.

Katirayifar, A.A., \& Rezvani, E. (2017). The effects of Iranian EFL learners' locus of control (external vs. internal) on their test anxiety and test scores. International Journal of Research Studies in Education, 6 (4), 57-66.

Kruk, M. (2015). Variations in motivation, anxiety and boredom in learning English in Second Life. The EUROCALL Review, 23 (2), 25-39.

Lefcourt, H. M. (2014). Locus of control: Current trends in theory \& research. Psychology Press.

MacIntyre, P. D. (2007). Willingness to communicate in the second language: understanding the decision to speak as a volitional process. The Modern Language Journal, 91(4), 564-576.

MacIntyre, P. D., \& Charos, C. (1996). Personality, attitudes, and affect as predictors of second language communication. Journal of Language and Social Psychology, 15(1), 3-26.

Manipuspika, Y.S. (2018). Correlation between anxiety and willingness to communicate in the Indonesian EFL context. Arab World English Journal, 9 (2), 200-217.

McCroskey, J. C. (1997). Reliability and validity of the willingness to communicate scale. Communication Quarterly, 40, 16-25.

McCroskey, J. C., \& Baer, J. E. (1985). Willingness to communicate: The construct and its measurement. Paper presented at the Annual Meeting of the Speech Communication Association, Denver, Co.

McCroskey, J. C., \& Richmond, V. P. (1990). Willingness to communicate: A cognitive view. In M. Booth-Butterfield (Ed.), Communication, cognition, and anxiety. USA:

Mohammed Sadiq, J. (2017). Anxiety in English language learning: A case study of English language learners in Saudi Arabia. English Language Teaching, 10 (7), 1-7. 
Mousavi, S.V., Rezaei, S., Atefi Karajvandi, S., Javanparast, H. (2018). The moderating role of internalexternal locus of control in the relationship between early maladaptive schemas and social anxiety in adolescents. Journal of Psychology, 22(2), 172-187.

Pattapong, K. (2010). Willingness to communicate in a second language: A qualitative study of issues affecting Thai EFL learners from students' and teachers' points of view. Doctoral dissertation, Louisiana State University, Louisiana, U.S.A.

Rahimi, A., \& Askari Bigdeli, R. (2014). Iranian EFL learners at loggerheads with perceived social support. Iranian Journal of Research in English Language Teaching, 1(3), 31-38.

Rotter, J. (1966). The social learning theory. Retrieved from http://psych.fullerton.edu/jmearns/rotter.htm

Sage.

Shao, K., Yu, W., \& Ji, Zh. (2013). An exploration of Chinese EFL students' emotional intelligence and foreign language anxiety. The Modern Language Journal, 97 (4), 917-929.

Talebi Rezaabadi, O. (2016). The relationships between social class, listening test anxiety and test scores. Advances in Language and Literary Studies, 7 (5), 147-156.

Valadi, A., Rezaee, A., \& Kogani Baharvand, P. (2015). The relationship between Language Learners' Willingness to Communicate and Their Oral Language Proficiency with Regard to Gender Differences. International Journal of Applied Linguistics \& English Literature, 4(5), 147-154.

Williams, M. \& Burden, R. (2002). Psychology for Language Teachers. Cambridge University Press.

Wu, C. P., \& Lin, H.J. (2016). Learning strategies in alleviating English writing anxiety for English language learners (ELLs) with limited English proficiency (LEP). English Language Teaching, 9 (9), 52-63.

Young, D.J. (1991). Creating a low-anxiety classroom environment: What does the language anxiety research suggest? Modern Language Journal, 75 (1), 425-439.

Yousefi, M., \& Kasaian, R. (2014). EFL learners' willingness to communicate: The interplay between language learning anxiety and language proficiency. International Journal of English Linguistics, 11(2), 23-34.

Zarrinabadi, N., \& Haidary, T. (2014). Willingness to communicate and identity styles of Iranian EFL learners. Procedia - Social and Behavioral Sciences, 98, 2010 - 2017.

Zhang, R., \& Zhong, J. (2012). The hindrance of doubt: Causes of language anxiety. Int. J. English Linguist, 2 (3), 27-33.

Zohrabi, M., \&Yousefi, M. (2016). The relationship between reflective teaching, willingness to communicate (WTC), and intrinsic motivation of Iranian advanced learners. International Journal on Studies in English Language and Literature (IJSELL), 4(2), 12-28.

\section{(ब) $\odot$}

BY NC This work is licensed under a Creative Commons Attribution-Noncommercial 4.0 International License 